\title{
Wild-Proso Millet Differentially Affects Canopy Architecture and Yield Components of 25 Sweet Corn Hybrids
}

\author{
Yim F. So
}

Department of Natural Resources and Environmental Sciences, University of Illinois, Urbana, IL 61801

\author{
Martin M. Williams II ${ }^{\mathbf{1}}$ \\ U.S. Department of Agriculture-Agricultural Research Service, Invasive \\ Weed Management Research, University of Illinois, 1102 South Goodwin \\ Avenue, Urbana, IL 61801
}

Jerald K. Pataky

Department of Crop Sciences, University of Illinois, Urbana, IL 61801

Additional index words. competition, crop tolerance, cultural weed control, Panicum miliaceum, morphological traits, wild-proso millet, yield loss

\begin{abstract}
Knowledge of cultivar-specific information on crop tolerance, the ability of the crop to endure competitive stress from weeds, has garnered recent interest in organic crop production. Twenty-five commercial sweet corn hybrids from nine seed companies were grown in the presence and absence of wild-proso millet (Panicum miliaceum L.) to 1) quantify tolerance in crop growth and yield to weed interference; 2) determine associations between tolerance in crop growth and yield; and 3) identify hybrids differing in tolerance to weed interference. Despite large differences in canopy architecture among hybrids, crop height and leaf uprightness were minimally affected by weed interference. In contrast, wild-proso millet interference reduced ear number $11 \%$ to $98 \%$ and ear mass $24 \%$ to $82 \%$ depending on the hybrid. The ability of a hybrid to make small growth adjustments in the presence of wild-proso millet appeared to have no relationship to yield tolerance. The least competitive hybrids were 'ACX1413', 'Optimum', 'Quickie', 'Spring Treat', and 'Sugar Buns'. The most competitive hybrids were 'Code128', 'Coho', 'EI Toro', 'EX 8716622', and 'Legacy'. Although some exceptions were observed, in general, the longer-maturity processing hybrids were more competitive with wildproso millet than the earlier-maturing fresh market hybrids.
\end{abstract}

Crop tolerance (CT) to weed interference is the ability of the crop to endure or avoid competitive stress from weeds without substantial reduction in growth or yield. Historically, CT has been a fundamental component of weed management, although the role of CT waned with the introduction of selective herbicides in the mid-20th century. In the last two decades, there has been renewed interest in more fully exploiting CT to reduce risk of weed control failure (Callaway, 1992; Lindquist and Mortensen, 1998). For instance,

\footnotetext{
Received for publication 8 Oct. 2008. Accepted for publication 19 Dec. 2008

We appreciate the technical assistance of Jim Moody, Bryan Warsaw, and the many students who helped on this study. Adam Davis and John Masiunas provided valuable comments on an earlier draft of this manuscript. We also thank seed companies listed in Table 1 for expertise and providing seed.

Mention of a trademark, proprietary product, or vendor does not constitute a guarantee or warranty of the product by the U.S. Dept. of Agriculture and does not imply its approval to the exclusion of other products or vendors that also may be suitable.

${ }^{1}$ To whom reprint requests should be addressed; e-mailmmwillms@illinois.edu
}

recent surveys documented $57 \%$ of conventionally managed sweet corn fields suffered yield loss as a result of weeds despite extensive reliance on herbicides for weed control (Williams et al., 2008c). An increasing prevalence of herbicide-resistant weeds and a growing organic market in several crops, including sweet corn, have fueled interest in CT playing a larger role in weed management. In agronomic crops such as wheat, rice, and soybean, efforts have been made to breed for cultivars more competitive with weeds (Jannink et al., 2001; Lemerle et al., 2006; Zhao et al., 2006).

Some corn hybrids vary in CT. In dent corn, which has been the subject of considerably more research on CT than sweet corn, several authors have identified canopy architecture traits important to $\mathrm{CT}$, including plant height, canopy density (Lindquist and Mortensen, 1998), leaf uprightness (Sankula et al., 2004), canopy closure rate, and maximum leaf area index (Lindquist et al., 1998). Weed interference can influence certain growth characteristics such as height (Cavero et al., 2000; Maddonni et al., 2002) and leaf azimuth orientation (Maddonni et al., 2002). In addition, the mere presence of weeds, and not direct competition for resources, can influ- ence crop growth. Rajcan et al. (2004) found that the presence of low-growing sod influenced light quality in such a way to alter dent corn growth early in the season. Even at low weed densities, differences were observed in sweet corn hybrid response to weed competition (Williams et al., 2006, 2008b).

The residual weed community (i.e., plants surviving management and persisting to harvest) of most sweet corn fields is often dominated by a small number of weed species. Wild-proso millet (Panicum miliaceum L.) is among the most abundant residual weed species observed in sweet corn (Williams et al., 2008c) and is a serious problem in a number of other horticultural and agronomic crops (Harvey and Porter, 1990; Wilson, 1993). Wild-proso millet has a long period of germination and seedling emergence, tolerates most herbicides used in sweet corn, and is a prolific seed producer.

Research on sweet corn-weed competition has included a relatively small number of hybrids (e.g., two to four hybrids) and has produced limited information on crop growth responses to weed interference. Moreover, the seed industry would like to identify cultivars with high CT suitable for organic production systems. The goal of this study was to examine considerably more hybrids than previously reported to gain a more complete understanding of sweet corn tolerance to weed interference. Using wild-proso millet as a model weed, specific objectives were to 1) quantify tolerance in crop growth and yield to weed interference; 2) determine the extent to which crop growth and yield tolerance variables are associated; and 3) identify hybrids differing in tolerance to weed interference.

\section{Materials and Methods}

Germplasm. Twenty-five commercial sweet corn hybrids were obtained from nine seed companies (Table 1). Plant breeders from each company were asked to provide up to three hybrids, which might differ in stress tolerance based on observations. All major endosperm types were included as well as hybrids used in both fresh and processing markets. Twenty-three hybrids were used the first year, and on industry request, two additional hybrids were included the second year. In addition, because the field had no history of wild-proso millet, seed of a local biotype was collected the previous year, airdried, and stored at room temperature for use in the following experiments.

Experimental approach. Field experiments were conducted in 2006 and 2007 at the University of Illinois South Farms on a Flanagan silt loam (fine, smectitic, mesic Aquic Argiudoll) soil averaging 3.8\% organic matter and $\mathrm{pH}$ of 5.8. A single field was divided into two halves, whereby half was used each year. The previous crop was soybean and the experimental site was fertilized at $129 \mathrm{~kg} \cdot \mathrm{ha}^{-1} \mathrm{~N}, 113 \mathrm{~kg} \cdot \mathrm{ha}^{-1} \mathrm{P}$, and 135 $\mathrm{kg} \cdot \mathrm{ha}^{-1} \mathrm{~K}$ in late March before planting. The experimental area was prepared for planting 
Table 1. Endosperm type, maturity, and primary market of 25 hybrids studied for crop tolerance to wildproso millet interference in Urbana, IL.

\begin{tabular}{|c|c|c|c|c|}
\hline Hybrid & Endosperm type $^{z}$ & Maturity (d) & Primary market & Company ${ }^{\mathrm{y}}$ \\
\hline$\overline{\mathrm{ACX} 1413 \mathrm{BC}}$ & sh2 & 71 & Fresh & Abbott and Cobb \\
\hline Beyond & $\operatorname{sh} 2$ & 81 & Fresh & Abbott and Cobb \\
\hline Cahill & sul & 73 & Processing & Rogers \\
\hline Code 128 & sul & 83 & Processing & General Mills \\
\hline Code 3 & sul & 78 & Processing & General Mills \\
\hline Code39 & $\operatorname{sh} 2$ & 86 & Processing & General Mills \\
\hline Coho & sul & 81 & Processing & Harris Moran \\
\hline DMC2184 & $\operatorname{sh} 2$ & 82 & Processing & Del Monte \\
\hline Dynamo & sul & 78 & Processing & Harris Moran \\
\hline El Toro & sul & 81 & Processing & Seminis \\
\hline EX 8716622 & $\operatorname{sh} 2$ & 79 & Processing & Seminis \\
\hline Harvest Gold & sul & 82 & Processing & Seminis \\
\hline Incredible & sel & 85 & Fresh & Crookham \\
\hline Legacy & sul & 85 & Processing & Harris Moran \\
\hline Luscious & sel & 75 & Fresh & Mesa Maize \\
\hline Mystic & $\operatorname{sh} 2$ & 82 & Processing & Del Monte \\
\hline Optimum & $\operatorname{sh} 2$ & 78 & Fresh & Crookham \\
\hline Overland & $\operatorname{sh} 2$ & 84 & Fresh & Rogers \\
\hline Precious Gem & sel & 80 & Fresh & Mesa Maize \\
\hline Quickie & sul & 68 & Fresh & Crookham \\
\hline Rocker & sul & 85 & Processing & Rogers \\
\hline SCH70064RR & $\operatorname{sh} 2$ & 79 & Fresh & IFSI \\
\hline Spirit & sul & 67 & Processing & Rogers \\
\hline Spring Treat & sel & 68 & Fresh & Mesa Maize \\
\hline Sugar Buns & sel/sul & 72 & Fresh & Crookham \\
\hline
\end{tabular}

${ }^{2}$ Endosperm type: su 1 = sugary 1 ; se 1 = sugary enhancer $1 ;$ sh $2=$ shrunken 2.

${ }^{y}$ Abbot \& Cobb, Inc., Feasterville, PA; Crookham Company, Caldwell, ID; Del Monte USA, Rochelle, IL; General Mills, LeSueur, MN; Harris Moran Seed Company, Nampa, ID; Illinois Foundation Seeds Inc., Champaign, IL; Mesa Maize, Olathe, CO; Rogers Seeds/Syngenta, Nampa, ID; Seminis Vegetable Seeds, DeForest, WI.

by two passes each of a field cultivator and disk harrow. The study was sprinkler-irrigated three times each in 2006 and in 2007.

The experimental design was a split plot with four replicates. Hybrid was the main plot factor, whereby eight-row $\times 9.2 \mathrm{~m}$ long main plots were planted on a $76-\mathrm{cm}$ row spacing at 10 seeds per meter of row using a cone planter. Presence or absence of wild-proso millet was assigned to subplots measuring four rows $\times 9.2$ $\mathrm{m}$. Seed of wild-proso millet were shallowly seeded at 115 nondormant seed $/ \mathrm{m}^{-1}$ of row in subplots directly into the center two rows using a cone planter immediately after crop planting. Sweet corn and wild-proso millet were planted on 29 May 2006 and 14 May 2007. After crop emergence, sweet corn plants were thinned to approximately five plants $/ \mathrm{m}^{-1}$ of row. In addition, wild-proso millet seedling population density was determined $16 \mathrm{~d}$ after emergence.

The study area was kept free of all weeds except wild-proso millet. Atrazine was applied pre-emergence at $1.68 \mathrm{~kg} \cdot \mathrm{ha}^{-1}$ ai to the entire study area, and $S$-metolachlor was applied preemergence at $1.78 \mathrm{~kg} \cdot \mathrm{ha}^{-1}$ ai to weed-free plots. After wild-proso millet emergence, $S$ metolachlor was applied at $1.78 \mathrm{~kg} \cdot \mathrm{ha}^{-1}$ ai to all plots and incorporated with interrow cultivation. Weeds emerging other than wild-proso millet were controlled with a single application of bentazon at $0.56 \mathrm{~kg} \cdot \mathrm{ha}^{-1}$ ai (2006 only) and weekly hand-weeding.

Data collection. Crop growth was measured in the center two rows of both weedfree and weedy subplots throughout the season. Growth stages were determined by counting the number of visible leaf collars and the appearance of reproductive organs (Ritchie et al., 2003). Plant height was measured from the soil surface to the apex at approximately V2, V6, and silk emergence (R1) stages. A visual rating of leaf uprightness at V6 and R1 was determined using a scale to describe the relative vertical position of the uppermost, fully emerged leaves (Fig. 1 ). Both weed-free and weedy treatments of each hybrid were harvested 18 to $20 \mathrm{~d}$ after silk emergence (R3) in weed-free plots. Marketable ears, measuring $4.5 \mathrm{~cm}$ or greater in diameter with husks, were hand-harvested from the center two rows over $6 \mathrm{~m}$ of row. Ear number and mass were recorded. Tip fill and kernel depth were measured from five randomly selected ears. weed interference was characterized for the following variables: height at $\mathrm{V} 2\left(\mathrm{CT}_{\mathrm{HtV} 2}\right)$, V6 $\left(\mathrm{CT}_{\mathrm{HtV} 6}\right)$, and $\mathrm{R} 1\left(\mathrm{CT}_{\mathrm{HtR} 1}\right)$; leaf uprightness at $\mathrm{V} 6\left(\mathrm{CT}_{\mathrm{LfV} 6}\right)$ and $\mathrm{R} 1\left(\mathrm{CT}_{\mathrm{LfR} 1}\right)$; and ear mass $\left(\mathrm{CT}_{\mathrm{Mass}}\right)$, ear number $\left(\mathrm{CT}_{\mathrm{Num}}\right)$, kernel depth $\left(\mathrm{CT}_{\mathrm{Kern}}\right)$, and tip fill $\left(\mathrm{CT}_{\text {Fill }}\right)$ at $\mathrm{R} 3$. For each hybrid within each replicate, crop tolerance was calculated as the response variable in weedy subplot divided by response variable in weed-free subplots expressed as a percentage.

All data were examined with Levene's test for homogeneity (Ott and Longnecker, 2001). Variances were found to be homogenous for all variables and met analysis of variance (ANOVA) assumptions of normality. ANOVA was conducted on each growth and yield tolerance variable, and the means were separated by the protected least significant difference test at $P<0.05$ with a
Statistical analyses. Crop tolerance to

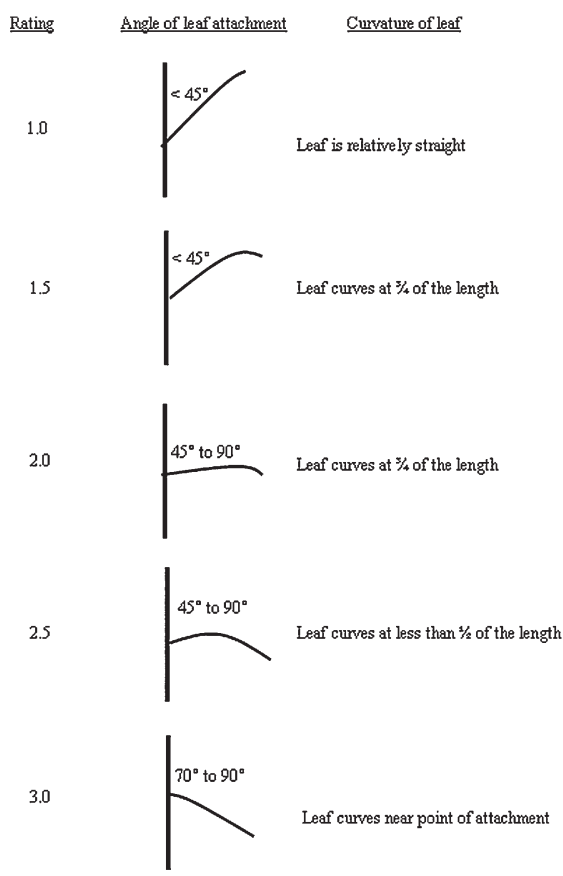

Fig. 1. Rating scale used to describe leaf uprightness of sweet corn hybrids.

Bonferroni correction (SAS Institute, 2002). In addition, linear associations between crop tolerance variables were quantified using Pearson correlation coefficients.

\section{Results and Discussion}

The weather was often hotter and drier than the 30-year average during most of the study. Mean monthly temperature was 0.3 and $1.4{ }^{\circ} \mathrm{C}$ above the 30 -year average in 2006 and 2007, respectively (Table 2). Including irrigation, total water supply was 31 and 97 $\mathrm{mm}$ below the 30-year average in 2006 and 2007, respectively. A dry start and end of each experiment was interrupted by aboveaverage water supply in July 2006 and June 2007. These rainfall and irrigation events preceded or coincided with tassle initiation and silk emergence, avoiding severe drought stress during pollination.

Crop and weed emergence coincided within $1 \mathrm{~d}$ of each other and crop population density after thinning was similar both years, averaging 4.7 plants $/ \mathrm{m}^{-1}$ of row. Wild-proso millet population density averaged 72 and 126 plants per meter of row in 2006 and 2007 , respectively. Wild-proso millet population density was within a range that previously caused significant yield losses in dent corn (Wilson and Westra, 1991) and sweet corn (Williams et al., 2008b).

Tolerance in crop growth. Plant height varied among hybrids throughout the experiment. For example, mean weed-free height among hybrids at V2 varied $\approx 2$-fold, and by $\mathrm{R} 1$, height ranged from 124 to $201 \mathrm{~cm}$ and 127 to $228 \mathrm{~cm}$ in 2006 and 2007, respectively. Differences in height among hybrids occurred earlier in the season and to a greater extent than similar research on fewer hybrids. 
Williams et al. (2006) reported three sugaryl (sul) sweet corn hybrids differed in canopy architecture only after V6 with the tallest hybrid averaging $65 \%$ more height than the shortest hybrid at R1. In this work, differences in height among hybrids were observed shortly after emergence and some hybrids were $83 \%$ to $107 \%$ taller than other hybrids by R1. In this study, variation among hybrids in early-season height reflects, in part, greater seedling vigor and seedling growth rate of sul endosperm types relative to shrunken2 (sh2) endosperm types (Azanza et al., 1996). Leaf uprightness also varied considerably among hybrids. Leaf uprightness of hybrids at V6 and R1 ranged such that some hybrids had leaves positioned high in the canopy (i.e., rating of 1.0), whereas leaves were oriented below the node to which they were attached in other hybrids (i.e., rating of 3.0).

Although not significant at $P=0.05$, wildproso millet interference resulted in a $6 \%$ reduction in overall plant height by $\mathrm{R} 1$ (data not shown). Previously, weed interference was observed to influence maximum crop height in early May-planted sweet corn (Williams and Lindquist, 2007); however, direction of sweet corn response varied with year. Weed interference from a tall weed community (averaging $64 \mathrm{~cm}$ ) resulted in increased crop height, likely as a result of a shade avoidance response, whereas weed interference from a shorter weed community (averaging $23 \mathrm{~cm}$ ) resulted in decreased crop height relative to a weed-free control (Williams and Lindquist, 2007; Williams and Masiunas, 2006). In this study, wild-proso millet that emerged with sweet corn ranged in height from $\approx 100$ to $150 \mathrm{~cm}$ at the time of sweet corn harvest. Taller hybrids in the present study had a large proportion of leaf area above wild-proso millet compared with the shorter hybrids that were overtopped by the weed.

Despite large differences in canopy architecture among hybrids, tolerance in height growth and leaf uprightness to weed interference were similar across hybrids $(P \geq 0.10)$. Although resources are often plentiful early in the season, presence of weeds can influence corn seedling growth. In the presence of grass sod (which was not competing for resources), certain dent corn seedlings grew taller, had larger leaves, and had a greater shoot-root ratio (Rajcan et al., 2004). Such shade avoidance responses are driven by the ability of the crop to detect light quality, which varies among dent corn hybrids (Maddonni et al., 2002). Light quality interacts with auxin in regulating development of leaf uprightness in corn seedlings, whereby far-red-enhanced light resulted in more horizontal leaves (Fellner et al., 2003). Fellner et al. (2003) also found that leaf uprightness of a modern corn hybrid, selected under high plant population densities, was less responsive to shade conditions than an older hybrid and attributed the result to fewer auxin receptors in the modern hybrid. The lack of substantial differences in tolerance among hybrids indicated that wild-proso millet inter- ference had a limited effect on plasticity in crop height growth and leaf uprightness.

The minimal effect of wild-proso millet interference on sweet corn growth is surprising. The early critical period of weed control in sweet corn (Williams, 2006) is consistent with some explanation beyond resource limitation (Rajcan et al., 2004). Most other weed species in the study were controlled preemergence and escapes were removed shortly after emergence. Wild-proso millet size may not have been large enough to alter light quality and induce changes in crop height and leaf uprightness. Alternatively, sweet corn detection of wild-proso millet may have resulted in changes in growth traits other than plant height and leaf uprightness such as leaf area and root:shoot ratio. Finally, a taller weed community than observed here may have enhanced a shade avoidance response in the sweet corn canopy.

Tolerance in crop yield. Weed-free yield varied among hybrids for all yield components $(P<0.01)$. For instance, weed-free ear mass ranged from 160 to $437 \mathrm{~g} /$ plant in 2006 and 280 to $561 \mathrm{~g} /$ plant in 2007. Weed-free ear number ranged from 0.7 to 1.8 ears/plant, tip fill was above $85 \%$, and kernel depth ranged from 8.4 to $11.2 \mathrm{~mm}$.

Wild-proso millet interference differentially reduced ear mass and ear number among hybrids. Although weed interference reduced ear number on average $48 \%$, range of response of $\mathrm{CT}_{\mathrm{Num}}$ was $25 \%$ to $65 \%$ in 2006 and $2 \%$ to $89 \%$ in 2007 (Table 3). Similar responses were observed for $\mathrm{CT}_{\text {Mass. }}$ In

Table 2. Monthly water supply and average daily temperature for the entire month of May, June, July, and August in 2006 and 2007 in Urbana, IL. ${ }^{z}$

\begin{tabular}{|c|c|c|c|c|c|c|c|c|}
\hline \multirow[b]{2}{*}{ Year } & \multirow[b]{2}{*}{ Month } & \multicolumn{2}{|c|}{ Water supply } & \multicolumn{3}{|c|}{ Avg daily temp } & \multicolumn{2}{|c|}{ Departure from avg } \\
\hline & & Rainfall & $\begin{array}{l}\text { Irrigation } \\
\text { m) ------- }\end{array}$ & Minimum & $\begin{array}{l}\text { Maximum } \\
-\left({ }^{\circ} \mathrm{C}\right)\end{array}$ & Mean & $\begin{array}{l}\text { Water } \\
(\mathrm{mm})\end{array}$ & $\begin{array}{c}\text { Temp } \\
\left({ }^{\circ} \mathrm{C}\right)\end{array}$ \\
\hline \multirow[t]{4}{*}{2006} & May & 78 & 0 & 11.0 & 22.4 & 16.7 & -44 & -0.3 \\
\hline & June & 42 & 25 & 15.8 & 27.9 & 21.9 & -40 & -0.2 \\
\hline & July & 199 & 8 & 19.0 & 30.7 & 24.8 & 88 & 0.9 \\
\hline & August & 76 & 0 & 18.4 & 28.3 & 23.3 & -35 & 0.6 \\
\hline \multirow[t]{4}{*}{2007} & May & 41 & 0 & 13.0 & 27.1 & 20.1 & -81 & 3.0 \\
\hline & June & 144 & 51 & 16.9 & 29.1 & 23.1 & 88 & 1.0 \\
\hline & July & 87 & 0 & 17.0 & 28.4 & 22.7 & -31 & -1.2 \\
\hline & August & 38 & 0 & 19.7 & 31.6 & 25.7 & -73 & 2.9 \\
\hline
\end{tabular}

${ }^{2}$ Departure from 30 -year average water supply and mean air temperature are included for reference.

Table 3. Values for crop tolerance to wild-proso millet interference measured in terms of yield components for 25 sweet corn hybrids studied in Urbana, IL. ${ }^{z}$

\begin{tabular}{|c|c|c|c|c|c|c|c|c|}
\hline \multirow[b]{3}{*}{ Hybrid } & \multicolumn{4}{|c|}{2006} & \multicolumn{4}{|c|}{2007} \\
\hline & $\mathrm{CT}_{\mathrm{Num}}^{\mathrm{y}}$ & $\mathrm{CT}_{\text {Mass }}$ & $\mathrm{CT}_{\text {Fill }}$ & $\mathrm{CT}_{\text {Kern }}$ & $\mathrm{CT}_{\mathrm{Num}}$ & $\mathrm{CT}_{\text {Mass }}$ & $\mathrm{CT}_{\text {Fill }}$ & $\mathrm{CT}_{\text {Kern }}$ \\
\hline & ----------- & ----------- & --------P & rcent of & weed-free & --------- & -------- & --------- \\
\hline$\overline{\mathrm{ACX} 1413}$ & 29 & 33 & 101 & 100 & 28 & 34 & 99 & 97 \\
\hline Beyond & 47 & 55 & 99 & 96 & 33 & 38 & 100 & 102 \\
\hline Cahill & 62 & 59 & 96 & 99 & 54 & 49 & 97 & 93 \\
\hline Code 128 & 55 & 66 & 100 & 92 & 81 & 71 & 97 & 89 \\
\hline Code 3 & 45 & 47 & 99 & 94 & 59 & 52 & 102 & 92 \\
\hline Code 39 & 48 & 55 & 100 & 95 & 63 & 68 & 94 & 91 \\
\hline Coho & 50 & 68 & 101 & 99 & 69 & 73 & 100 & 97 \\
\hline DMC2184 & 65 & 61 & 100 & 93 & 48 & 49 & 100 & 93 \\
\hline Dynamo & 52 & 58 & 94 & 107 & 89 & 67 & 97 & 94 \\
\hline El Toro & 63 & 64 & 103 & 91 & 82 & 68 & 97 & 91 \\
\hline EX 8716622 & 63 & 66 & 100 & 100 & 61 & 48 & 100 & 86 \\
\hline Harvest Gold & 45 & 53 & 101 & 100 & 65 & 60 & 96 & 92 \\
\hline Incredible & 47 & 56 & 99 & 98 & 40 & 56 & 92 & 94 \\
\hline Legacy & 62 & 76 & 100 & 103 & 77 & 72 & 100 & 100 \\
\hline Lucious & 49 & 51 & 98 & 98 & 55 & 41 & 97 & 101 \\
\hline Mystic & 65 & 67 & 100 & 99 & 50 & 51 & 96 & 97 \\
\hline Optimum & $-^{x}$ & - & - & - & 14 & 34 & 99 & 96 \\
\hline Overland & - & - & - & - & 47 & 53 & 98 & 94 \\
\hline Precious Gem & 50 & 59 & 99 & 95 & 59 & 58 & 99 & 93 \\
\hline Quickie & 39 & 35 & 97 & 93 & 40 & 44 & 90 & 103 \\
\hline Rocker & 62 & 62 & 102 & 93 & 73 & 61 & 98 & 96 \\
\hline SCH70064RR & 53 & 65 & 101 & 96 & 44 & 47 & 100 & 97 \\
\hline Spirit & 59 & 53 & 99 & 100 & 50 & 46 & 97 & 96 \\
\hline Spring Treat & 27 & 25 & 97 & 93 & 5 & 31 & $-^{w}$ & - \\
\hline Sugar Buns & 25 & 37 & 99 & 96 & 2 & 18 & - & - \\
\hline Least significant difference & 36 & 39 & NS & NS & 30 & 25 & 10 & NS \\
\hline
\end{tabular}

${ }^{\mathrm{z}}$ Mean values for crop tolerance to wild-proso millet interference are separated using Bonferroni-corrected least significant difference.

${ }^{\mathrm{y}} \mathrm{CT}_{\mathrm{Num}}=$ tolerance in ear number; $\mathrm{CT}_{\text {Mass }}=$ tolerance in ear mass; $\mathrm{CT}_{\text {Fill }}=$ tolerance in tip fill; $\mathrm{CT}_{\mathrm{Kern}}=$ tolerance in kernel depth.

${ }^{x}$ Hybrids Optimum and Overland were added in 2007

${ }^{w}$ An insufficient number of marketable ears were produced in weedy plots to measure kernel depth and tip fill. NS $=$ nonsignificant. 
contrast, hybrids were largely similar for $\mathrm{CT}_{\text {Fill }}$ and $\mathrm{CT}_{\text {Kern }}$. Williams and Masiunas (2006) reported tolerance in sweet corn yield and ear traits to giant ragweed (Ambrosia trifida L.) interference. Marketable ear mass was among yield variables most affected by giant ragweed interference, whereas effects on tip fill and kernel depth were minimal (Williams and Masiunas, 2006). Bonaparte and Brawn (1974) reported that of 16 traits in four dent corn hybrids, grain yield per plant and yield per unit area were the most elastic traits, whereas kernel row number and ear height varied the least. Similar results were observed in the present study as evidenced by $\mathrm{CT}_{\text {Num }}$ and $\mathrm{CT}_{\text {Mass }}$ varying significantly among hybrids, whereas $\mathrm{CT}_{\text {Fill }}$ and $\mathrm{CT}_{\text {Kern }}$ varied least.

Sweet corn yield in the presence of wildproso millet was positively correlated with weed-free yield, although higher-yielding hybrids were not inherently better at tolerating wild-proso millet interference than lower-yielding hybrids. For instance, for each $10 \mathrm{-g}$ increase in weed-free ear mass, there was a 9.2- to 10.2-g increase in weedy ear mass yield (data not shown). Similar positive correlations between weedy and weed-free values occurred with other yield components. Using many of the same hybrids, a detailed analysis of the effects of underlying principal crop canopy factors on weed biomass and fecundity is reported by So et al. (2009).

Correlations among tolerances in growth and yield. Few associations were observed among tolerances in crop growth and yield to wild-proso millet interference. Crop tolerance for height at R1 was weakly associated with CT for ear mass in 2007 as evidenced by a correlation coefficient of 0.23 ; however, this association was not observed in 2006 (Table 4). Weak and inconsistent results between the 2 years suggests that the subtle effects of weed interference on crop height growth and leaf uprightness were largely independent of yield tolerance to wild-proso millet. Traits that improve light interception such as height and leaf area distribution contribute to yield stability in the presence of weed interference (Callaway, 1992; Lindquist and Mortensen, 1998; Lindquist et al., 1998; Williams et al., 2008b). Wild-proso millet interference either failed to influence crop growth or influenced traits other than plant height and leaf uprightness, thereby limiting the extent to which tolerances in growth and yield variables were related.

Most tolerant versus least tolerant hybrids. Sweet corn hybrids most tolerant to wild-proso millet interference were mainly processing hybrids. Five processing hybrids with the highest $\mathrm{CT}_{\text {mass }}$ across years included 'Code128', 'Coho', 'El Toro, 'EX 8716622', and 'Legacy' (Table 3). Sweet corn hybrids that were least tolerant to wild-proso millet interference were five fresh market hybrids, including 'ACX1413', 'Optimum', 'Quickie', 'Spring Treat', and 'Sugar Buns'. Hybrids most and least tolerant to weed interference differ in maturity. The five most tolerant hybrids mentioned are considered $79 \mathrm{~d}$ or

Table 4. Correlation coefficients among growth and yield values for tolerance in sweet corn to wild-proso millet interference. ${ }^{\mathrm{z}}$

\begin{tabular}{lccccccrrr}
\hline & $\mathrm{CT}_{\mathrm{HtV} 2}$ & $\mathrm{CT}_{\mathrm{HtV} 6}$ & $\mathrm{CT}_{\mathrm{HtR} 1}$ & $\mathrm{CT}_{\text {LfV6 }}$ & $\mathrm{CT}_{\mathrm{LfR} 1}$ & $\mathrm{CT}_{\text {Mass }}$ & $\mathrm{CT}_{\text {Num }}$ & $\mathrm{CT}_{\text {Kern }}$ & $\mathrm{CT}_{\text {Fill }}$ \\
\hline $\mathrm{CT}_{\mathrm{HtV} 2 \mathrm{y}}{ }^{\mathrm{z}}$ & - & 0.02 & -0.07 & 0.10 & 0.06 & -0.14 & -0.11 & $-0.33^{*}$ & -0.08 \\
$\mathrm{CT}_{\mathrm{HtV} 6}$ & -0.02 & - & 0.11 & 0.00 & 0.00 & 0.17 & 0.05 & -0.02 & 0.02 \\
$\mathrm{CT}_{\mathrm{HtR} 1}$ & 0.05 & -0.03 & - & -0.07 & -0.02 & 0.03 & 0.09 & -0.05 & 0.00 \\
$\mathrm{CT}_{\mathrm{LfV} 6}$ & 0.15 & -0.05 & -0.03 & - & -0.06 & -0.10 & -0.03 & 0.12 & -0.08 \\
$\mathrm{CT}_{\text {LfR } 1}$ & -0.04 & -0.12 & 0.05 & 0.11 & - & 0.14 & 0.10 & -0.02 & 0.01 \\
$\mathrm{CT}_{\text {Mass }}$ & -0.04 & -0.20 & $0.23^{*}$ & -0.13 & 0.17 & - & $0.86^{*}$ & -0.05 & 0.09 \\
$\mathrm{CT}_{\text {Num }}$ & 0.07 & -0.17 & 0.18 & -0.10 & 0.08 & $0.79 *$ & - & 0.18 & 0.09 \\
$\mathrm{CT}_{\text {Kern }}$ & 0.19 & 0.02 & 0.08 & -0.07 & -0.04 & 0.17 & 0.13 & - & 0.10 \\
$\mathrm{CT}_{\text {Fill }}$ & -0.18 & 0.05 & 0.00 & -0.13 & 0.01 & 0.18 & 0.06 & $-0.27 *$ & -
\end{tabular}

${ }^{\mathrm{z}}$ Coefficients above and below the diagonal are for 2006 and 2007 , respectively. Significant $(P$ value $\leq$ 0.05 ) coefficients are identified with an asterisk.

${ }^{\mathrm{y}} \mathrm{CT}_{\mathrm{HtV} 2}=$ tolerance in height at $\mathrm{V} 2 ; \mathrm{CT}_{\mathrm{HtV} 6}=$ tolerance in height at $\mathrm{V} 6 ; \mathrm{CT}_{\mathrm{HtR} 1}=$ tolerance in height at $\mathrm{R} 1$; $\mathrm{CT}_{\mathrm{LfV} 6}=$ tolerance in leaf uprightness at $\mathrm{V} 6 ; \mathrm{CT}_{\mathrm{LfR} 1}=$ tolerance in leaf uprightness at $\mathrm{R} 1 ; \mathrm{CT}_{\mathrm{Mass}}=$ tolerance in ear mass; $\mathrm{CT}_{\mathrm{Num}}=$ tolerance in ear number; $\mathrm{CT}_{\mathrm{Kern}}=$ tolerance in kernel depth; $\mathrm{CT}_{\mathrm{Fill}}=$ tolerance in tip fill.

longer hybrids, whereas four of the five least tolerant hybrids are $72 \mathrm{~d}$ or shorter hybrids (Table 1). However, maturity alone does not fully account for differences in CT among hybrids. For instance, $73-d$ maturity 'Cahill' was among the most tolerant hybrids for marketable ear mass. In addition, 81 -d hybrid 'Beyond' was among the least tolerant hybrids for yield traits in 2007. Moreover, a relatively poor association was observed between thermal time to silking and CT among hybrids (data not shown).

This study investigated CT of 25 sweet corn hybrids and found a greater range of crop response than previously reported. Williams et al. (2008a) reported yield of 'Rocker' was less influenced by variation in wild-proso millet interference compared with yield of 'Cahill'. Compared with a broader range of germplasm in the present study, 'Cahill' and 'Rocker' have relatively similar crop tolerances to wild-proso millet interference. In addition, yield of 'Spirit' was found to be less tolerant to weed interference compared with yield of 'WHT2801' and 'GH2547' (Williams et al., 2008b). With the exception of $R p-G$ rust resistance, hybrids 'GH2547' and 'Rocker' are essentially identical. In the present work, neither 'Rocker' nor 'Spirit' were among the most or least tolerant hybrids to weed interference. Differences in $\mathrm{CT}$ among sweet corn hybrids were recently identified; however, CT in yield varies to a greater extent among hybrids than previously reported.

Of the 25 hybrids tested for CT, no hybrid escaped yield loss as a result of weed interference; however, some hybrids endured wild-proso millet interference considerably better than others. The hybrids with the greatest $\mathrm{CT}$ were dominated by later-maturing, processing hybrids, whereas early-maturing hybrids were often less tolerant to wild-proso millet interference. Wild-proso millet interference had little effect on crop height and leaf uprightness, suggesting weed interference was insufficient to induce major changes in these components of crop canopy architecture. Competitive ability of hybrids would be valuable information in weed management decision-making, particularly where weed control options are limited such as in organic production systems.

\section{Literature Cited}

Azanza, F., A.B. Zur, and J. Juvik. 1996. Variation in sweet corn characteristics associated with stand establishment and eating quality. Euphytica 87:7-18.

Bonaparte, E.E.N.A. and R.I. Brawn. 1974. The effect of intraspecific competition on the phenotypic plasticity of morphological and agronomic characters of four maize hybrids. Ann. Bot. (Lond.) 39:863-869.

Callaway, B.M. 1992. A compendium of crop varietal tolerance to weeds. Am. Alt. Agr. 7:169-180

Cavero, J., C. Zaragoza, L. Bastiaans, M.L. Suso, and A. Pardo. 2000. The relevance of morphological plasticity in the simulation of competition between maize and Datura stramonium. Weed Res. 40:163-180.

Fellner, M., L.A. Horton, A.E. Cocke, N.R. Stephens, E.D. Ford, and E.V. Volkenburgh. 2003. Light interacts with auxin during leaf elongation and leaf angle development in young corn seedlings. Planta 216:366-376.

Harvey, R.G. and D.J. Porter. 1990. Wild-proso millet (Panicum miliaceum) control in soybeans (Glycine max) with postemergence herbicides. Weed Technol. 4:420-424.

Jannink, J.L., N.R. Jordan, and J.H. Orf. 2001. Feasibility of section for high weed suppressive ability in soybean: Absence of tradeoffs between rapid initial growth and sustained later growth. Euphytica 120:291-300.

Lemerle, D., A. Smith, B. Verbeek, E. Koetz, P. Lockley, and P. Martin. 2006. Incremental crop tolerance to weeds: A measure for selecting competitive ability in Australian wheats. Euphytica 149:85-95.

Lindquist, J.L. and D.A. Mortensen. 1998. Tolerance and velvetleaf (Abutilon theophrasti) suppressive ability of two old and two modern corn (Zea mays) hybrids. Weed Sci. 46:569-574

Lindquist, J.L., D.A. Mortensen, and B.E. Johnson. 1998. Mechanisms of corn tolerance and velvetleaf suppressive ability. Agron. J. 90:787792 .

Maddonni, G.A., M.A. Otegui, B. Andrieu, M. Chelle, and J.J. Casal. 2002. Maize leaves turn away from neighbors. Plant Physiol. 130:11811189.

Ott, R.L. and M. Longnecker. 2001. An introduction to statistical methods and data analysis. 5 th Ed. Duxbury, Pacific Grove, CA. p. 368-371. 
Rajcan, I., K.J. Chandler, and C.J. Swanton. 2004. Red-far-red ratio of reflected light: A hypothesis of why early-season weed control is important in corn. Weed Sci. 52:774-778.

Ritchie, S.W., J.J. Hanway, G.O. Benson, and J.C. Herman. 2003. How a corn plant develops. Iowa State Univ. of Sci. and Technol. Coop. Ext. Serv, Spec. Rept. No. 48 (revised).

Sankula, S., M.J. VanGessel, and R.R. Mulford. 2004. Corn leaf architecture as a tool for weed management in two production systems. Weed Sci. 52:1026-1033.

SAS Institute. 2002. User's guide: Statistics. SAS Institute, Cary, NC.

So, Y.F., M.M. Williams, II, J.K. Pataky, and A.S. Davis. 2009. Principal canopy factors of sweet corn and relationships to competitive ability with wild-proso millet (Panicum miliaceum). Weed Sci. (in press).
Williams, M.M., II. 2006. Planting date influences critical period of weed control in sweet corn. Weed Sci. 54:928-933.

Williams, M.M., II, R.A. Boydston, and A.S. Davis. 2006. Canopy variation among three sweet corn hybrids and implications for light competition. HortScience 41:1449-1454.

Williams, M.M., II, R.A.R.A. Boydston, and A.S. Davis. 2008a. Crop competitive ability contributes to herbicide performance in sweet corn Weed Res. 48:58-67.

Williams, M.M., II, R.A. Boydston, and A.S. Davis. 2008b. Differential tolerance in sweet corn to wild-proso millet (Panicum miliaceum) interference. Weed Sci. 56:91-96.

Williams, M.M., II and J.L. Lindquist. 2007. Influence of planting date and weed interference on sweet corn growth and development. Agron. J. 99:1066-1072.
Williams, M.M., II and J.B. Masiunas. 2006. Functional relationships between giant ragweed (Ambrosia trifida) interference and sweet corn yield and ear traits. Weed Sci. 54:948-953.

Williams, M.M., II, R.L. Rabaey, and C.M. Boerboom. 2008c. Residual weeds of sweet corn in the north central region. Weed Technol. 22: 646-653.

Wilson, R.G. 1993. Wild proso millet (Panicum miliaceum) interference in dry beans (Phaseolus vulgaris). Weed Sci. 41:607-610.

Wilson, R.G. and P. Westra. 1991. Wild proso millet (Panicum miliaceum) interference in corn (Zea mays). Weed Sci. 39:217-220.

Zhao, D.L., G.N. Atlin, L. Bastiaans, and J.H.J Spiertz. 2006. Cultivar weed-competitiveness in aerobic rice: Heritability, correlated traits, and the potential for indirect selection in weedfree environments. Crop Sci. 46:372-380. 